\title{
NOVAS ESPÉCIES DE COUSSAREA AUBL. E FARAMEA AUBL. (RUBIACEAE, TRIBO COUSSAREAE)
}

\author{
Mario Gomes ${ }^{1}$
}

Recebido em 29/03/2001. Aceito em 08/03/2003

\begin{abstract}
RESUMO - (Novas espécies de Coussarea Aubl. e Faramea Aubl. (Rubiaceae, tribo Coussareae)). Quatro novas espécies da família Rubiaceae, relacionadas à tribo Coussareae são descritas e ilustradas. São elas: Coussarea bocainae; Faramea hymenocalyx; F. paratiensis e F. picinguabae. Os táxons aqui apresentados tiveram como base material coletado na Serra do Parati, situada na divisa entre os Estados do Rio de Janeiro e São Paulo, nas proximidades do litoral. Essa serra integra o Parque Nacional da Serra da Bocaina e possui cobertura vegetal predominante da Floresta Pluvial Atlântica, sendo essa a área de distribuição e o hábitat dos novos táxons.
\end{abstract}

Palavras-chave - Rubiaceae, Coussarea, Faramea, Floresta Pluvial Atlântica

\begin{abstract}
New species from Coussarea Aubl. and Faramea Aubl. (Rubiaceae, tribe Coussareae)). Four new species of the Rubiaceae, tribe Coussareae are described and illustrated: Coussarea bocainae; Faramea hymenocalyx; F. paratiensis and F. picinguabae. They are based on the material collected in the Parati Mountains, located on the border between Rio de Janeiro and São Paulo States, near the coast. This mountainous area is part of the Serra da Bocaina National Park, which is covered mainly by Atlantic Rain Forest. These new taxa are found in this forest within the Park.
\end{abstract}

Key words - Rubiaceae, Coussarea, Faramea, Atlantic Rain Forest

\section{Introdução}

A Serra do Parati, em quase toda sua extensão, inclui-se na área do Parque Nacional da Serra da Bocaina. Esse segmento, que integra o sistema orográfico da Serra do Mar, situa-se entre as coordenadas geográficas $23^{\circ} 00^{\prime}$ $23^{\circ} 30^{\prime} \mathrm{S}$ e $44^{\circ} 30^{\prime}-45^{\circ} 00^{\prime} \mathrm{W}$. O divisor de águas dessa serra corresponde ao trecho da divisa dos
Estados do Rio de Janeiro e São Paulo, próximo do mar. Nas suas vertentes, orientadas no sentido NE-SW, estendidas entre os municípios de Parati (RJ) e Ubatuba/Picinguaba (SP), respectivamente, encontram-se outras unidades de conservação, como a Área de Proteção Ambiental de Cairuçu (RJ) e o Parque Estadual da Serra do Mar (SP). Faz-se menção também à Estação Experimental do Instituto Agronômico

\footnotetext{
1 mario-gomes@bol.com.br
} 
de Campinas, Núcleo Picinguaba, como área de mata preservada.

Nos domínios em que se encerram as referidas unidades foram realizadas excursões que trouxeram expressiva quantidade de material botânico. Esse material foi enviado para diversos herbários e está sendo utilizado na elaboração da Flora Fanerogâmica do Estado de São Paulo (em andamento) e da Flórula da APA Cairuçu (Marques et al. 1997).

A região exibe clima tropical, com variações de quente a subquente, super-úmido, sem período de seca, numa faixa onde são registrados os maiores totais pluviométricos do Brasil (Nimer 1989). A cobertura vegetal tem predomínio da Floresta Pluvial Atlântica e encontra-se em bom estado de conservação.

Estudos realizados nessa localidade revelam que Rubiaceae está relacionada entre as famílias com maior representatividade, avolumando-se tanto em número de indivíduos, quanto em riqueza de táxons (Silva \& Leitão Filho 1982; Marques 1997).

A tribo Coussareae, na área delimitada, compõe-se de treze táxons específicos e infraespecíficos, sendo quatro pertencentes ao gênero Coussarea e nove a Faramea.

$\mathrm{Na}$ busca de identificação do material coletado nessa região, observou-se que as características de alguns espécimes de ocorrência restrita àquela localidade não se enquadravam satisfatoriamente em outras espécies já descritas.

Os quatro táxons, um de Coussarea e três de Faramea, que até o momento têm registro de ocorrência somente para a região da Serra do Parati, estão sendo considerados como novos para a ciência e, neste trabalho, faz-se a sua apresentação.

\section{Material e métodos}

Tipos nomenclaturais e coleções históricas, citados em obras clássicas de espécies cujas descrições indicavam alguma proximidade com o material indeterminado foram requisitados a herbários nacionais e estrangeiros, detentores das referidas coleções, para comparação.

Analisaram-se exemplares das seguintes espécies: Coussarea contracta (Walpert) Müll. Arg., C. fiebrigii K. Krause, C. schiffneri Zahlbr., C. virens Müll. Arg., Faramea bahiensis Müll. Arg., F. cardiophylla Standl., F. coarinensis Müll. Arg., F. cordifolia Glaz., F. cyanea Müll. Arg., F. diversifolia Müll. Arg., F. heterophylla Müll. Arg., F. hyacinthina Mart., F. latifolia (Cham. \& Schltdl.) DC., F. leucocalyx Müll. Arg., F. longifolia Benth., F. luziana Müll. Arg., F. macra Müll. Arg., F. malmei Standl., F. marginata Cham., F. martiana Müll. Arg., F. nitida Benth., F. obtusifolia Müll. Arg., F. oxyclada Müll. Arg., F. pachydictyon Müll. Arg., F. paulensis Zahlbr., F. percyanea Zahlbr., F. platyclada Müll. Arg., F. platypoda Müll. Arg., F. pohliana Müll. Arg., F. saldanhaei Glaz., F. tamberlikiana Müll. Arg., F. tetragona Müll. Arg., F. torquata Müll. Arg., F. umbellifera (Presl.) Müll. Arg., F. warmingiana Müll. Arg., F. weddellii Standl. e F. xanthina Müll. Arg.

Os epítetos específicos apresentados neste trabalho referem-se: 1) ao complexo montanhoso da região - bocainae; 2) ao município e localidade em que ocorrem os holótipos paratiensis e picinguabae e 3) à consistência membranácea do cálice - hymenocalyx.

\section{Resultados e discussão}

Coussarea bocainae M.Gomes, sp. nov. Fig. 1.

Forma foliorum similis eis C. capitatae (Benth.) Müll. Arg., sed majoribus dimensionibus, thyrsis amplioribus, non compactis et habitu majore; formam, dimensiones et portiones florum ut in $C$. contracta (Walpert) Müll. Arg. habet.

Tipos: BRASIL. São Paulo: Ubatuba, Estação Experimental do Instituto Agronômico de Campinas, 5/XII/1978, A.F. Silva 8 (Holotypus UEC; Isotypus: RB); Rio de Janeiro: Parati, APA Cairuçú, morro das 


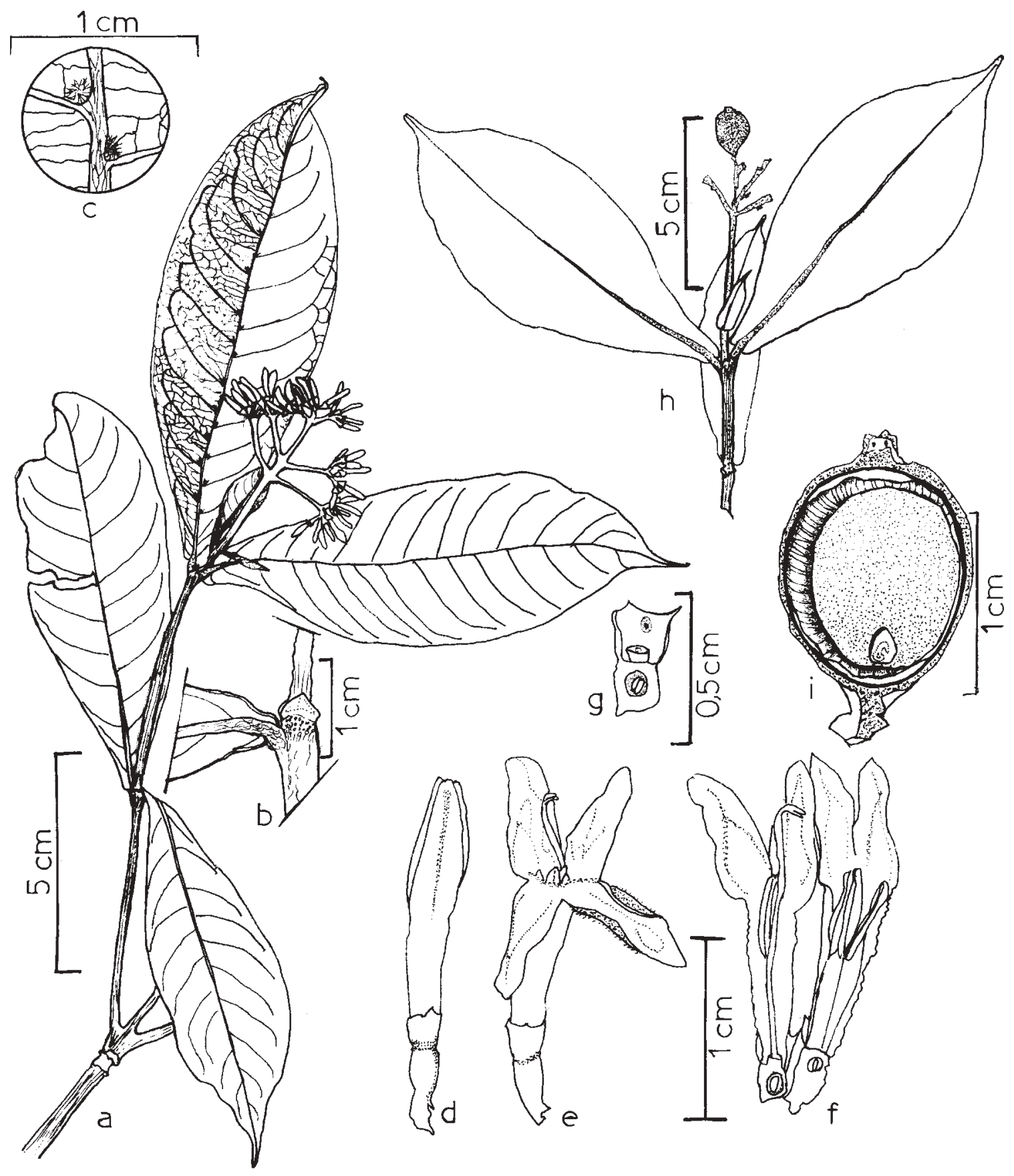

Figura 1. Coussarea bocainae M. Gomes: a. ramo florífero; b. detalhe do ramo e estípula; c. domácias; d. botão floral; e. flor aberta; f. flor dissecada; g. cálice e ovário em corte longitudinal; h. ramo frutífero; i. fruto em corte longitudinal (a, b, c, d, e, f, g Silva 8; h, i Marquete 1641). 
Carneiras, 18/III/1993, E.A. Filho et al. 149 (Paratypus RB; Isoparatypi: SP, UEC); Parati, Vargem Grande, trilha para pedra da Jamanta, 14/IV/1994, R. Marquete 1.641 (Paratypus RB; Isoparatypi: $\mathrm{K}, \mathrm{NY})$.

Árvore 7-10m alt.; ramos delgados, comprimidos, angulosos, pálidos, estriados. Estípulas triangular-agudas, pálido-marginadas, ligeiramente mais largas que longas, ca. 5mm compr., minutamente verruculosas. Folhas subsésseis; pecíolo robusto, verruculoso, ca. $2 \mathrm{~mm}$ compr.; limbo elíptico-obovado ou lanceolado-obovado, coriáceo, base truncada a cordada, estreitada, ápice abruptamente acuminado, 10-17×3,5-6cm; nervura central robusta, proeminente na face inferior, 10-14 pares de nervuras secundárias, delgadas, ascendentes, domácias em tufo de pêlos. Tirsos terminais piramidais; ramos delgados; pedúnculo 2,5-4,5cm compr.; brácteas foliáceas, linear-lanceoladas, 1,5-3,5cm compr.; ramos secundários $1-1,5 \mathrm{~cm}$ compr.; pedicelos ca. $1 \mathrm{~mm}$ compr. Flores ca. 1,5cm compr.; botões clavados, tetrágonos; cálice pálido, obcônico, denteado, dentes triangulares agudos, ca. $2 \mathrm{~mm}$ compr.; corola infundibuliforme, lobos ovados, ápice arredondado, 1/2-mesmo comprimento do tubo; estames inseridos no terço superior do tubo, anteras semi-exsertas; estilete ultrapassando a fauce da corola. Fruto drupóide, oblongo a ligeiramente obovado, levemente comprimido lateralmente, até $1,5 \mathrm{~cm}$ compr.

Florece em dezembro, tendo sido encontrada com frutos desenvolvidos em março e abril.

As folhas de Coussarea bocainae M. Gomes assemelham-se às de $C$. capitata (Benth.) Müll. Arg. no que se refere à forma e consistência do limbo, base e ápice. Entretanto, na espécie nova, geralmente as folhas são de dimensões maiores, o porte é arbóreo, os tirsos são mais amplos, visivelmente ramificados e não compactos, como em $C$. capitata. As flores aqui descritas possuem forma, dimensões e proporções como as de $C$. contracta (Walpert) Müll. Arg., as demais estruturas, porém, apresentam-se distintas entre ambas.

Faramea hymenocalyx M. Gomes (sectio Tetramerium), sp. nov.

Fig. 2.

Haec nova species maxime calycem membranaceum, late campanulatum offert, lobis undulatis, similibus eis F. campanellae Müll. Arg., ex sectione Homaloclados, sed non corolloideum; cymae ramis fere trifidis, basi par foliorum minorum quam ea ex ramis, basi cordata et alabastris cylindraceis.

Tipos: BRASIL. divisa dos Estados do Rio de Janeiro/São Paulo, limite de municípios Parati/Ubatuba, morro do Cuscuzeiro, mata de encosta entre 600 e 1.200m.s.m., 20/XI/1990, C. Farney \& M. Nadruz 2.479 (Holotypus RB, Isotypus IAC); Rio de Janeiro: Parati, APA Cairuçu, Laranjeiras, caminho para praia do Sono, 12/V/1994, R. Reis et al. 120 (Paratypus $\mathrm{RB}$, Isoparatypus $\mathrm{SP}$ ); subida para o morro do Corisco, 13/V/1991, L.S. Sylvestre et al. 554 (Paratypus RB).

Arbusto a pequena árvore 1,5-5m alt.; ramos delgados, jovens comprimidos. Estípulas decíduas, triangular-arredondadas, verruculosas, aristas dorsais ca. $3 \mathrm{~mm}$ compr. Folhas com pecíolo canaliculado, 0,5-1,3cm compr.; limbo nigrescente em material herborizado, elíptico, oblongo a lanceolado, com formas intermediárias, base aguda, obtusa ou truncada, ápice acuminado, margem recurva, 9-15,5×2,5-6cm, nervação delgada, ligeiramente proeminente na face inferior, 7-11 pares de nervuras secundárias bifurcadas a ca. $1 \mathrm{~cm}$ da margem, nervuras intersecundárias subparalelas. Folhas na base das inflorescências menores, subsésseis, base cordada e amplexicaule, ápice acuminado. Cimas terminais corimbosas, 5-radiadas, ramos delgados, ligeiramente comprimidos; pedúnculo 1,5-4cm compr.; ramos laterais em tríades, raro mais ramificados; pedicelos até $5 \mathrm{~mm}$ compr. Flores ca. 1cm compr.; botões florais bem jovens cilíndricos, mais desenvolvidos com ápice tetrágono, sub-alado; cálice e hipanto obcônico 


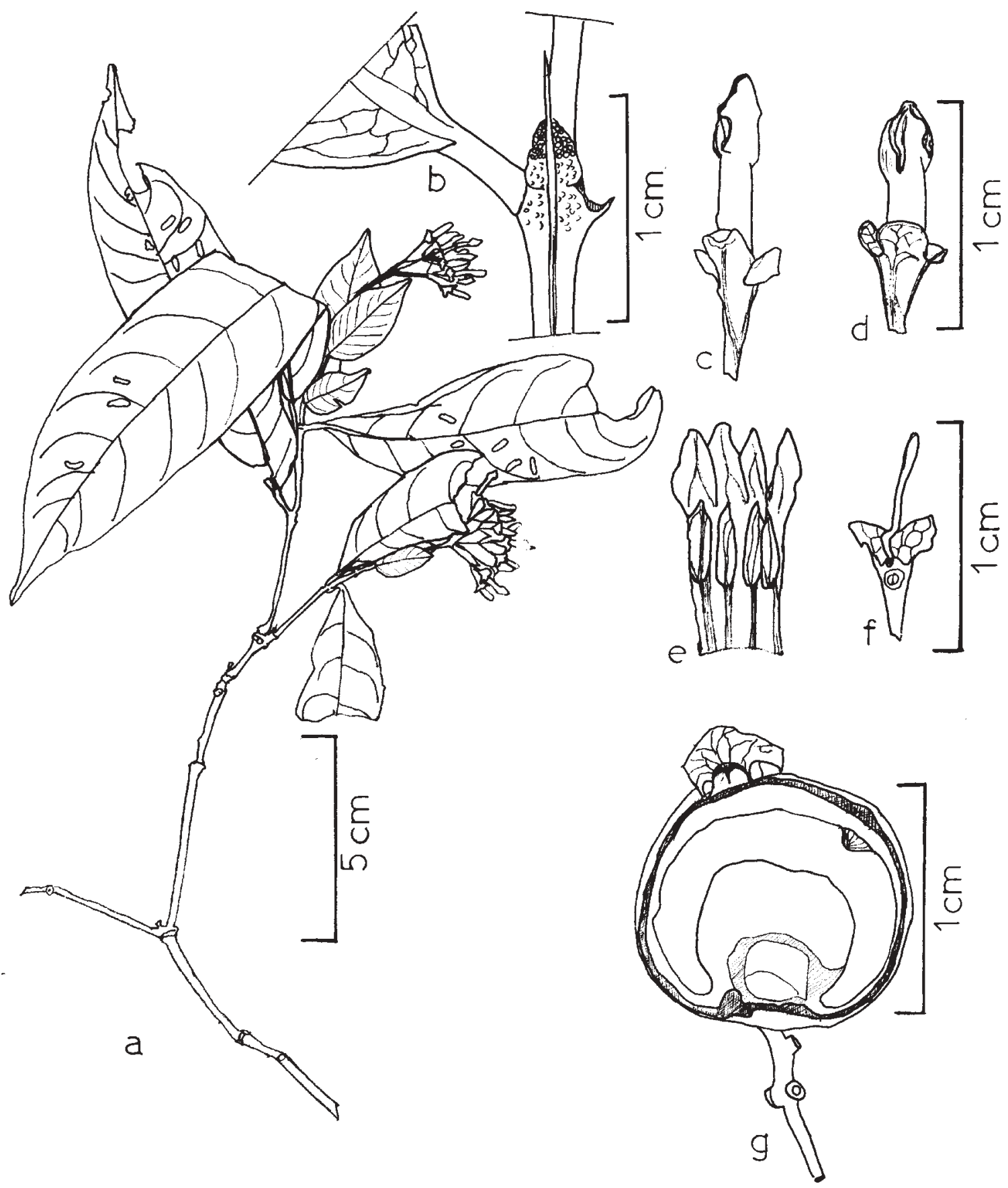

Figura 2. Faramea hymenocalyx M. Gomes: a. ramo florífero; b. detalhe do ramo e estípula; c-d. botões florais; e. corola dissecada e androceu; f. cálice e gineceu em corte longitudinal; g. fruto em corte longitudinal (a-f Farney \& Nadruz 2479 \& Nadruz; g Sylvestre 554). 
na base e largo-campanulado mais acima, ca. $3 \mathrm{~mm}$ compr., lobos ondulados, membranáceos, nervação conspícua; tubo da corola cilíndrico, lobos ovóides ca. 1/2 do compr. do tubo; estames inseridos no terço inferior ou médio do tubo, anteras ca. $3 \mathrm{~mm}$ compr.; disco do ovário arredondado, estilete ultrapassando a fauce da corola. Fruto drupóide, com epicarpo liso, base truncada, ca. $1 \mathrm{~cm}$ compr., cálice persistente acrescente.

Encontrada com flores em novembro e com frutos desenvolvidos e maduros em maio.

Faramea hymenocalyx M. Gomes possui cálice membranáceo, largo-campanulado com lobos ondulados. Essas características fazem com que se assemelhe ao de F. campanella Müll. Arg. da seção Homaloclados. Entretanto, na espécie nova, o cálice não se apresenta corolínico, o que, entre outras características, a relaciona à seção Tetramerium. Em F. campanela o cálice é vistoso, sendo essa a principal característica da seção à qual está vinculada. Além da forma e consistência do cálice, nenhuma outra estrutura possui semelhança entre estas espécies.

O cálice membranáceo, as cimas com ramos geralmente em tríades, tendo na base um par de folhas menores que as dos ramos, mesmo na fase de frutificação, com base cordada e os botões florais cilíndricos, sub-alados à altura dos lobos, completam o conjunto dos principais caracteres de F. hymenocalyx.

Faramea paratiensis M. Gomes (sectio Tetramerium) sp. nov.

Fig. 3.

Hae nova species flores similes eis $F$. tetragonae Müll. Arg., offert, sed ramis cylindraceis aut compressis, foliis visibiliter petiolatis basi cuneata usque ad cordatam, sed non amplexicauli, et nervis tenuibus patentibus; cymae ramulis exiguis et fructibus ample majoribus.

Tipos: BRASIL. Rio de Janeiro: Parati, APA Cairuçu, estrada para praia do Sono,
30/VI/1993, R. Marquete et al. 1117 (Holotypus $\mathrm{RB}$, Isotypi $\mathrm{BR}, \mathrm{K}, \mathrm{NY})$; morro do Carrapato, 30/VIII/1994, M. G. Bovini et al. 524 (Paratypus RB); Laranjeiras, cachoeira das Pedras, caminho para praia do Sono, 8/XII/1993, T. Konno et al. 387 (Paratypus RB, Isoparatypi R, RUSU); córrego dos Micos, morro da Pedra Rolada, 19/X/1993, R. Marquete 1254 (Paratypus RB); estrada para condomínio Laranjeiras, 6/VIII/1994, R. Marquete 1941 (Paratypus RB, Isoparatypi HRCB, MO, W); caminho para praia do Sono, 9/VIII/1994, $R$. Marquete 1981 (Paratypus RB, Isoparatypi B, IAC, WU); trilha para Serra do Parati, margem do rio Corisco, 28/IX/1996, R. Mello-Silva \& D.Y.A.C. Santos 1240 (Paratypus SPF, Isoparatypus RB); fazenda São Roque, trilha para Cunha (São Paulo), 13/XII/1988, B. Rapoport et al. 63 (Paratypus RB); São Paulo: Ubatuba, Estação Experimental do IAC, 12/XI/1993, C. Koschnitzke et al. 29.805 (Paratypus UEC, Isoparatypus SP).

Arbusto a árvore, 1-10m alt.; ramos jovens comprimidos lisos, desenvolvidos cilíndricos estriados. Estípulas longo-orbiculares, lisas, aristas dorsais setáceas, 0,5-2cm compr. Folhas com pecíolo robusto estriado canaliculado, às vezes nigrescente, $0,5-1,5 \mathrm{~cm}$ compr.; limbo oliváceo, coriáceo, oblongo, elíptico a lanceolado, provido de minúsculas e numerosas pontuações translúcidas por toda superfície, base cordada a cuneada, ápice acuminado, $8-24 \times 1,5-8,5 \mathrm{~cm}$, ca. 11 pares de nervuras secundárias delgadas, patentes, encurvadas, proeminentes na face inferior, com intersecundárias subparalelas. Folhas na base das inflorescências bem menores, subsésseis, ovadas, base cordada, ápice acuminado. Cimas terminais corimbosas, 5-radiadas; ramos robustos, comprimidos; pedúnculo $1,5-5 \mathrm{~cm}$ compr.; ramos laterais em tríades e em mônades; pedicelos $0,5-1,5 \mathrm{~cm}$ compr. Flores ca. $2 \mathrm{~cm}$ compr.; cálice obcônico, denteado, ca. $2 \mathrm{~mm}$ compr.; tubo da corola cilíndrico, lobos longo-triangulares, mesma medida do tubo; estames 


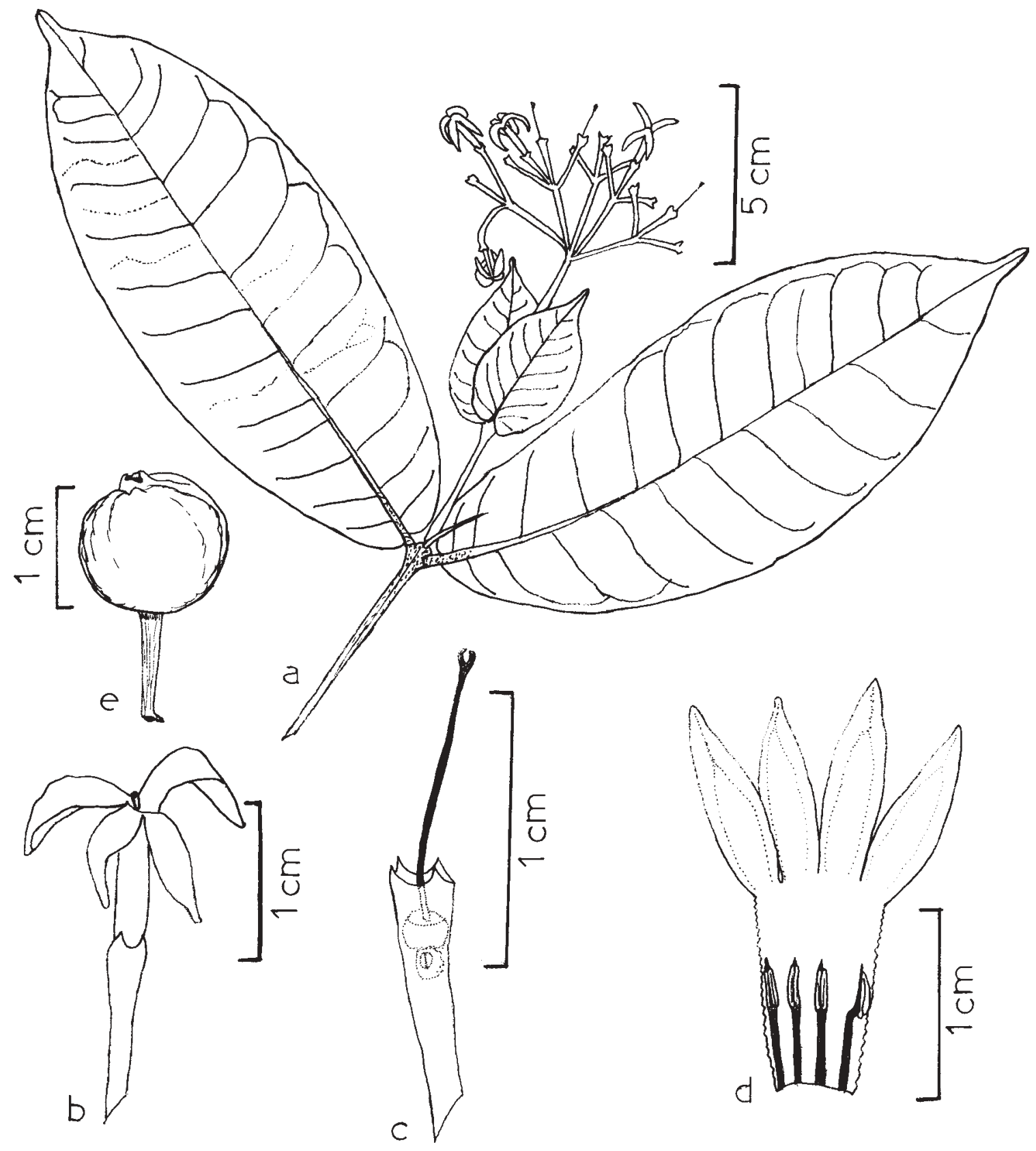

Figura 3. Faramea paratiensis M. Gomes: a. ramo florífero; b. flor aberta; c. cálice e gineceu; d. corola dissecada e androceu; e. fruto. a, b, c, d Rapoport 63; e Konno 387. 
inclusos, inseridos no terço médio do tubo, filetes robustos, anteras apiculadas; disco do ovário arredondado, estilete ultrapassando a fauce da corola, ápice bilobado. Fruto drupóide, globoso, base truncada, epicarpo liso ou com estrias longitudinais, até $1,5 \mathrm{~cm}$ compr., cálice persistente.

Pode ser encontrada com flores de junho a dezembro, frutos desenvolvidos ou maduros registrados em março, maio e dezembro.

A espécie nova apresenta flores semelhantes às de Faramea tetragona Müll. Arg. As características que $F$. paratiensis possui, e que a fazem diferir dessa, são os ramos cilíndricos ou comprimidos, folhas visivelmente pecioladas, com base cuneada a raramente cordada, mas não amplexicaule, e nervuras delgadas, patentes, cimas com ramos secundários menos desenvolvidos e frutos atingindo maior desenvolvimento.

Faramea picinguabae M. Gomes (sectio Tetramerium), sp. nov.

Fig. 4.

Species proxima F. tetragonae Müll. Arg. et $F$. paratiensis M. Gomes, sed foliis magis membranaceis basi acuta usque ad obtusam; flores similes eis citatis nuper, sed inserti cymis 3-5-radiatis ramis lateralibus generatim monadibus et pedunculo breviore.

Tipos: BRASIL. São Paulo: Ubatuba, Picinguaba, Parque Estadual da Serra do Mar, margens do rio da Fazenda, 29/XII/1992, M. Sanchez \& F. Pedroni 29 (Holotypus HRCB; Isotypus: RB) idem, 13/I/1997, I.S.M. Gajardo s.n. (Paratypus HRCB 27821, Isoparatypus RB); Ubatuba, 1/VII/1959, M. Kuhlmann 4.629 (Paratypus SP, Isoparatypus IAC); mata da cachoeira do Macaco, 25/VI/1986 (fl., fr.), M. Kirizawa 1696 (Paratypus SP, Isoparatypus RB); Km 11 da vila Picinguaba, 150-400m.s.m., 1987, Edna s.n. (Paratypus SPF 67.685); 1987, Edna s.n. (Paratypus SPF 67.688, Isoparatypus: $\mathrm{K})$.
Plantas glabras. Arbusto ca. 4m alt.; ramos delgados, comprimidos, lisos ou ligeiramente estriados. Estípulas triangulares, ápice arredondado, $3 \mathrm{~mm}$ compr., aristas dorsais setígero-filiformes $0,5-1 \mathrm{~cm}$ compr. Folhas com pecíolo canaliculado, nigrescente, 0,5-1cm compr.; limbo subcoriáceo a membranáceo, lanceolado a elíptico-lanceolado, base obtusa a aguda, ápice acuminado-cuspidado, margem às vezes recurva, $7,5-21 \times 2-8 \mathrm{~cm}$, nervura central delgada, proeminente na face inferior, 10-14 pares de nervuras secundárias delgadas, patentes, arcuado-ascendentes, unidas próximo à margem, com inter-secundárias e reticulação tênues. Folhas na base das inflorescências bem menores, sésseis, ovadas, base cordada. Cimas terminais corimbosoumbeliformes, 3-5 radiadas; pedúnculo comprimido, 1,5-2cm compr.; ramos secundários em mônades, raro em tríades; pedicelos 2-5mm compr. Flores 2,5-3cm compr.; botões ovados, ápice obtuso; cálice obcônico, ca. $3 \mathrm{~mm}$ compr., lobos triangulares, acuminados, reflexos; corola com tubo cilíndrico-infundibuliforme, lobos longo ovados, 1/2-2/3 do comprimento do tubo; estames inclusos, inseridos no terço superior do tubo, anteras lineares, apiculadas, ca. $5 \mathrm{~mm}$ compr.; disco do ovário arredondado, estilete filiforme, estigma bilobado. Fruto drupóide, comprimido dorsiventralmente, epicarpo liso, ca. $1 \mathrm{~cm}$ compr., $1,3 \mathrm{~cm}$ larg.

$\mathrm{Na}$ fase de frutificação, as folhas apresentam-se nitidamente maiores do que no período de floração. Isto sugere uma fase de caducifolia antes da fase fértil.

Espécie próxima à Faramea tetragona Müll. Arg. e F. paratiensis M. Gomes. Diferencia-se dessas por ter folhas de consistência mais membranácea, com base aguda a obtusa; flores semelhantes às das espécies citadas, porém inseridas em cimas 3-5 radiadas, com ramos laterais em geral em mônades e pedúnculo mais curto. 


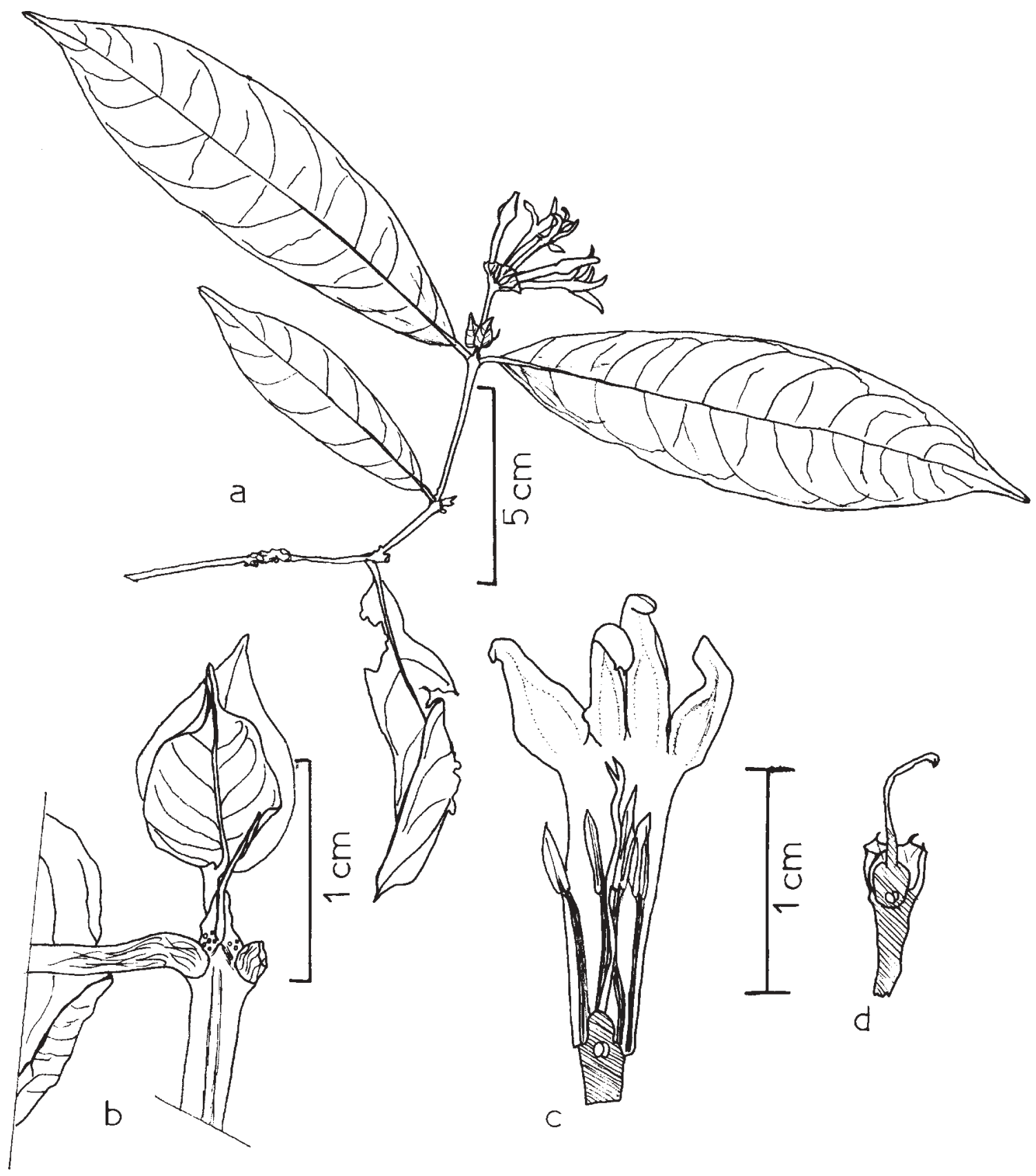

Figura 4. Faramea picinguabae M. Gomes: a. ramo florífero; b. detalhe do ramo com estípula e folhas da base da inflorescência; c. flor dissecada; d. cálice e gineceu em corte longitudinal (Sanchez \& Pedroni 29). 


\section{Agradecimentos}

À Dra. Dorothy Sue Dunn Araújo, do Departamento de Ecologia da UFRJ, pela revisão do Abstract; ao Prof. Dr. Miguel Barbosa do Rosário, do Departamento de Letras Clássicas da UFRJ, por seu valioso auxílio na revisão do texto em latim; à Dra. Nilda Marquete F. Silva, Curadora do Herbário do Instituto de Pesquisas Jardim Botânico do Rio de Janeiro (RB) e sua equipe, por terem gentilmente franqueado as dependências e serviços do herbário; ao Prof. Ronaldo Marquete e Dra. Ângela Vaz (IBGE/JBRJ) e ao Projeto Restinga (JBRJ), que cederam seus laboratórios para a realização deste trabalho.

\section{Referências bibliográficas}

Marques, M. C. M. 1997. Mapeamento da cobertura vegetal e listagem das espécies ocorrentes na Área de Proteção Ambiental de Cairuçu, Parati, RJ. Pp. 1-96. Série Estudos e Contribuições n. 13. Instituto de Pesquisas Jardim Botânico do Rio de Janeiro, Rio de Janeiro.

Marques, M. C. M.; Vaz, A. S. F. \& Marquete, R. (org.) 1997. Flórula da APA Cairuçu, RJ: espécies vasculares. Pp. 1-576. Série Estudos e Contribuições n. 14. Instituto de Pesquisas Jardim Botânico do Rio de Janeiro, Rio de Janeiro.

Nimer, E. 1989. Climatologia do Brasil. Departamento de Recursos Naturais e Estudos Ambientais. IBGE, Rio de Janeiro.

Silva, A. F. \& Leitão Filho, H. F. 1982. Composição florística e estrutura de um trecho de mata atlântica de encosta no município de Ubatuba (São Paulo, Brasil). Revista Brasileira de Botânica 5(1/2): 43-52. 